\title{
An Antenniform Extra Appendage in Dilophus tibialis, Loew.
}

\author{
By \\ William Morton Wheeler, Ph. D., \\ Assistant Professor of Embryology, University of Chicago, Chicago, Illinois, U. S. $A$. \\ With plate XVI.
}

Eingegangen am 31. Januar 1896.

Among the many peculiarities of insects, there is one which is not often mentioned, probably because it is of a negative character. This is the great rarity of those excessive variations which we are in the habit of calling monsters. Countless specimens of insects, representing thousands of species, annually come under the observation of skillful specialists, but nevertheless Hexapod terato$\log y$, although it comprises some of the most remarkable and instructive cases - e. g. the cases of lateral hermaphroditism observed in some Lepidoptera - may be said to make but very little progress. This is not due to insufficient study or to lack of interest on the part of entomologists, but to the great scarcity of really note-worthy anomalies. The Vertebrata, far less abundantly represented in species and individuals, not infrequently exhibit extremely aberrant variations such as double monsters, but no one, to my knowledge, has ever yet recorded the occurrence of a double insect embryo or imago, and the only double larva that $I$ have seen mentioned in the literature is a Chironomus which had two heads, the bifurcation of the body beginning at the fifth posteephalic segment ${ }^{1}$ ).

1) This case was described by Weyenbergh: Über ein zweiköpfiges Monstrum (Larve von Chironomus) und iber Insektenmonstra iberhaupt. Stett. Entom. Zeitg. 34. Jahrg. 1873. pag. 452-458. 
This relatively great scarcity of monsters may be due, in part, to the fact that the Insecta as a group are exceedingly old, and very early in their phylogeny attained to great fixity in the main features of their organization, so that only minor characters are affected by the almost endless variation which the group exhibits today. This being the case, any tendency to depart widely from the morphological norm may be weaker, and for that reason less liable to assert itself than in some other groups of animals which, like the Vertebrata, have retained a higher degree of plasticity down to a much more recent period in their phylogenetic history. The relative scareity of monsters may also be due to the fact that all insects have to run the gauntlet of several ecdyses, and in very many instances have to undergo an elaborate metamorphosis besides. The success of these processes must depend on the accurate working of very intricate and delicate mechanisms, so that any sudden or profound deviation from the norm may very readily lead to their inhibition, and henee also to the death of the individual before sexual maturity. Thus ecdysis and metamorphosis constitute a very efficient means of eliminating the weak and unfit, a category to which monsters, especially those of an extreme type, unquestionably belong.

It follows from these considerations that no little interest must attach to all those cases in which insects exhibit some marked deformity and nevertheless succeed in completing their metamorphosis. Of such a nature is the case to be described in the following pages, a female Dilophus tibialis, Loew, which I captured with the sweep-net, September $11^{\text {th }} 1895$, together with other specimens of the same species. These flies were abundant in the high grass which borders Hunter's Creek where it descends from the Wind River Mountains (Western Wyoming) at an altitude of about 8000 feet ${ }^{1}$ ).

I believe that I have identified the species correctly although LoEw's description ${ }^{2}$ ) is based only on the female. LoEw describes the legs of his specimens thus: „Coxae anticae luteo-rufae,

1) The day following I found the same species equally abundant in the meadows of the Two-gwo-tee-e Pass at an even greater altitude, and subsequently, Sept. $16^{\text {th }}$, after crossing the Continental Divide and descending the Pacific slope, the species was again met with in smaller numbers in the wide meadows which form the northern shore of Jackson's Lake.

2) Diptera Americae septentrionalis indigena. Berolini 1561. Centuria 9, 61. 
trochanteribus nigris, posteriores cum trochanteribus nigrae, femora luteo-rufa, apice omnium posteriorumque basi nigris vel nigrofuscis; tibiae nigrae, etc." This will apply to most of the females which I have collected. A considerable number of my specimens, however, have the legs and coxae almost entirely black, there being only a little red on the outer faces of the fore coxae and on the corresponding portions of the fore femora. Some specimens even have the fore femora entirely black, a variation which approaches the male. This sex was not seen by Loew and may be briefly described from specimens taken in coitu with females of the three colorvarieties:

\section{Dilophus tibialis, Loew. Male.}

Body, legs and antennae entirely black, shining. Head large and round, with the usual characters of the sex; the rather long pile on the eyes black; ocellar tubercle prominent. Hairs on the thorax and abdomen dirty white; halteres black with paler pedicels; tip of the abdomen turned up; anterior pecten of the thorax uninterrupted, with narrow, pointed teeth. Wings with a narrower and less transparent stigma than in the female, and the infuscation extending over fewer veins near the costa.

Length of body $3.5-4.5 \mathrm{~mm}$., length of wings $3.5-4.5 \mathrm{~mm}$.

LoEw's specimens were from Sitka, but this cannot invalidate the specifie identity, inasmuch as my specimens were taken at a high altitude and therefore under conditions not nnlike those of Alaska.

As the anomalous specimen was of small size and was hurriedly killed and packed away with many other Diptera, to be mounted and studied at leisure after my return to Chicago, I did not, unfortunately, observe it in a living condition. It is normal in every respect - even to the red coloring of the fore coxae and the femora - with the exception of the fore coxa of the right side, which bears a long 9-jointed extra appendage. This appendage (Figs. 1 and 2 ) is inserted on the anterior face of the coxa near its distal end. It is of a deep black color except the bases of the first and second joints, which are red like the coxa. The basal joint is the longest and has a narrower basal end than any of the succeeding joints, which grow somewhat broader and shorter towards the tip of the appendage. The terminal joint is constricted near its apex and may consist of two joints fused, but this is doubtful. All the joints are covered with short black hairs. At the base of the appendage 
there is a thin, hyaline, chitinons membrane, occupying the angle formed by the first joint, the tip of the coxa, the trochanter and the proximal end of the femur. This membrane, if very rigid, would have rendered impossible any movement of the joints just mentioned; in the softened specimen, however, the membrane proved to be quite flexible, so that during life the leg probably had considerable freedom of movement. The separate joints of the adventitious appendage were also freely movable on one another, whether voluntarily or not in the living animal, cannot, of course, be determined. The curvature of the organ, which was even more pronounced before the drawings were made, is easily accounted for, since it enabled the organ to assume the only position in which it could be carried without interfering with the movements of the right fore leg in walking and the right wing in flying.

Such being the structure of the adventitious appendage, the question arises: How is it to be interpreted? There are two normal insect appendages with which it may be compared - the palpus and the antenna. It cannot be a palpus, because it contains too many joints, and because its insertion on the anterior face of the coxa differs considerably from the insertion of the palpus on the maxilla or on the labium in insects with these mouth-parts well developed. The antennary nature of the organ is far more evident. In fact, if the appendage were detached and presented to any entomologist, he would not fail to call it an antenna. But a difficulty presents itself when we come to compare this adventitious antenna with the true antenna on the head of the Dilophus (Fig. 1). The former is then seen to be much longer and thicker, and to consist of only 9 individually longer joints, whereas the latter is 10 -jointed and much smaller. It is certainly remarkable that an insect should have a well developed appendage of a different character from any of those which it normally possesses. The study of this difference leads to two considerations: First it may be possible to explain the smaller number of joints in the adventitious appendage. If the apical joint is really double there would be no discrepancy; if it is not, the number may be due to a law formulated by BATESon 1 ) for cases of extra legs in insects viz. "The parts found in extra legs are those parts which are in the normal leg peripheral to the

1) Materials for the Study of Variation treated with Especial Regard to Discontinuity in the Origin of Species. London 1894. pag. 476. 
point from which the extra legs arise, and, as a rule no more. Though in extra legs parts may be deficient or malformed, structures which in the normal leg are central to the point of origin of the extra legs are not repeated in them. "This law is not absolute, but it may very well have regulated the formation of the extra antenniform appendage in the Dilophus. On this supposition the coxa would represent the first antennal joint and the typical number of 10 joints would be accounted for.

The second consideration refers to the discrepancy in the size and form of the joints between the true antenna and the adventitous appendage. The joints of the former are broad and very short and closely crowded together; in the latter they are much longer than broad. Among the Nematocera Orthorhapha, to which great group of Diptera the Bibionid Diloph us belongs, the antennae in by far the greater number of families have the joints longer than broad. The Bibionidae and Simulidae almost certainly exhibit a secondary condition in their short and crowded joints and in the small size of the whole antenna. Hence the more elongate form in the anomaly under consideration would seem to be due to atavism, or a tendency to revert to the more ancestral antennal type still retained by the great majority of the Nematocera.

The cases of double and paired extra appendages in insects have recently been collated by BATESON ${ }^{1}$ ). Of the former be enumerates 120, of the latter 110 cases. A paper by ScudDER ${ }^{2}$ ), containing descriptions of 8 cases, seems to have been overlooked by Bateson. But in this whole number of 238 cases, the supernumerary appendages, whether they be legs, antennae or palpi, are always of the same nature as the appendages to which they are united. There appears to be no case on record like the Dilophus, in which the two parts of the appendage are of a different character. We are therefore justified in assuming that some other formative component must have been operating in this particular case besides that of mere reduplication ${ }^{3}$ ).

In our search for this eomponent, it will be necessary to turn to another series of anomalies which have also been carefully collated

1) 1. c. pag. 475 et seq. and pag. 543 et seq.

2) A Decade of Monstrous Beetles. Psyche. Vol. 6. 1891. pag. 89-93. Pl. 2.

3) The word scomponent is here nsed in a sense similar to that adopted by Rovx in his »Einleitung to these Archives, pag. 5. 
by Bateson 1). At pag. 84 he says: „It is desirable and indeed necessary that such Variations which consist in the assumption by one member of the meristic series, of the form or characters proper to other members of the series, should be recognized as constituting a distinct group of phenomena. $T_{0}$ these phenomena which are particularly common among plants, and which Masters has called * metamorphic «, Bateson applies the name homoeosis2). As illustrations of this anomaly two very significant cases may be cited: 1. The case described by $\mathrm{KraATz}^{3}$ ) of a saw-fly in which the left antenna is represented by a leg, and 2. the famous case, first described by MiLne Eowards ${ }^{4}$, and subsequently figured by Howes ${ }^{5}$,

1) l. e.

2. Phenomena of apparently the same nature as those called phomoeotic by BATESON, have been called pheteromorphic « by LOEB in two very interesting papers: Untersuchungen zur physiologischen Morphologie der Thiere. 1. Über Heteromorphose. Würzburg 1891, 1 Taf. pag. 1-79, and 2. Organbildung and Wachsthum. Würzbarg 1892. 2 Taf. pag. 1-81. LoFs's definition, as given in his second paper, is as follows: $I$ Ich bezeichnete den Ersatz eines verlorenen Organs durch ein anderes, vom verlorenen nach Form und Lebenserscheinungen verschiedenes als Heteromorphose; unter Regeneration verstehe ich den Ersatz eines verlorenen durch ein ihm gleiches Organ." As will be seen, LoEB's term heteromorphosis lays greatest stress on the dissimilarity of the artificially produced structures to organs occupying the same position under normal conditions, whereas BATEson's term homoeosis lays greatest stress on the similarity of abnormal structures to normal organs in other parts of the body. The cases collated by BATEson are anomalies (extreme saltatory variations) occurring in a state of nature - »Nature's experiments « ; IOEB has succeeded in producing heteromorphosis (in Hydroids) in the laboratory. In the former instances the causes are very obscure, in the latter they seem, to some extent at least, to be definite external stimuli, such as gravity, ete. Since in the production of the one set of phenomena, viz. in natural anomalies, heredity (germ-plasma) may be a very potent factor, whereas in the latter set of phenomena it is relatively unimportant, there may be reason for retaining both appellations. This question I shall not venture to decide. LoEB's term emphasizes the physiological aspect and certainly has priority, BATEsox's term is morphological and therefore more applicable to the special case which I am considering.

3) Über eine merkwürdige Monstrosität bei Cimbex axillaris (Hymenont.). Deutsch. Entom. Zeitsehr. 20. Jahrg. 1976. pag. 37i. Taf. 1 Fig. $a, a, b:$ BATEson's case No. 75.

4) Sur un cas de trangformation du pédoncle oculaire en une antenne. observé chez une Langouste. Compt. Rend. 59. 1864. pag. 710-712.

5) Exhibition of, and remarks npon, an original drawing of the head of an abnormal Palinuras (P. penicillatus). Proc. Z. Soc. London 1887. pag. 468-470 Fig.; Bateson's case No. 31. 
of a Decapod crustacean in which the left eye and its stalk were replaced by an antenna-like flagellum.

In these cases there is a substitution of one organ by another normally belonging to a different segment of the body. In the Dilophus we likewise have a condition which agrees with these typical examples of homoeosis in the assumption by one member of a meristic series of a character (the antenna) proper to another member (the antennary, or deutocerebral segment) of the series, but there is this important difference: in the Dilophus there is no substitution, but an addition. For this reason, and because the essential peculiarity of the abnormality is clearly recognized by Bateson, I would broaden the original definition and distinguish two kinds of homoeosis - a substitutional and a redundant, or adventitious homoeosis.

These two kinds of homoeosis have an important bearing on the question of homologies. The substitutional form is very generally supposed to have great weight in clinching the evidence for any given case of serial homology, or homodynamy. Thus the abovementioned Palinurus appears to confirm the view that the eyestalks are homodynamous with the other cephalic appendages (antennae), and the homodynamy of cephalic with postoral appendages (thoracic legs) seems evident from a consideration of the anomalous Cimbex. Conversely, the occurrence of two organs in the same segment is usually taken to preclude their homodynamy. In other words, what seems to be proved by substitutional homoeosis in the case of Cimbex, would seem to be disproved by redundant homoeosis in the case of Dilophus. Fortunately, in this particular instance, embryology and comparative anatomy furnish so much evidence to show that the antenna is actually the serial homologue of the fore leg, that we cannot lay much stress on the apparent dyshomology suggested by Dilophus. Nevertheless, cases of this kind, if sufficiently numerous, must ultimately affect our notions of homodynamy, providing abnormalities may be assumed to throw any side light whatsoever on the operations that condition normal structures.

To sum up in conclusion the main inferences drawn from a study of the abnormal Dilophus, at least four components seem to have coopperated in forming the prothoracic appendage of the right side:

1. A bifurcation of the primitive Anlage (imaginal disc) of the right prothoracic limb. 
268 William Morton Wheeler, An Antenniform Extra Appendage etc.

2. A divergence in the character of the two rami of the organ.

3. The assumption on the part of the anterior ramus of the form of an antenna (redundant homoeosis).

4. An atavistic tendency, in obedience to which the anterior ramus does not assume the form of the antenna peculiar to the Bibionidae, but conforms to the more ancestral antennal type common to most of the Orthorhapha Nematocera.

University of Chicago, January $5^{\text {th }}, 1896$.

\section{Explanation of Plate XVI.}

Fig. 1. Female Dilophus tibialis, Loew with abnormal prothoracic appendage, seen from the right side. Magnified 18 diameters.

Fig. 2. Prothoracic leg with its antenniform appendage. Magnified 70 diameters. 


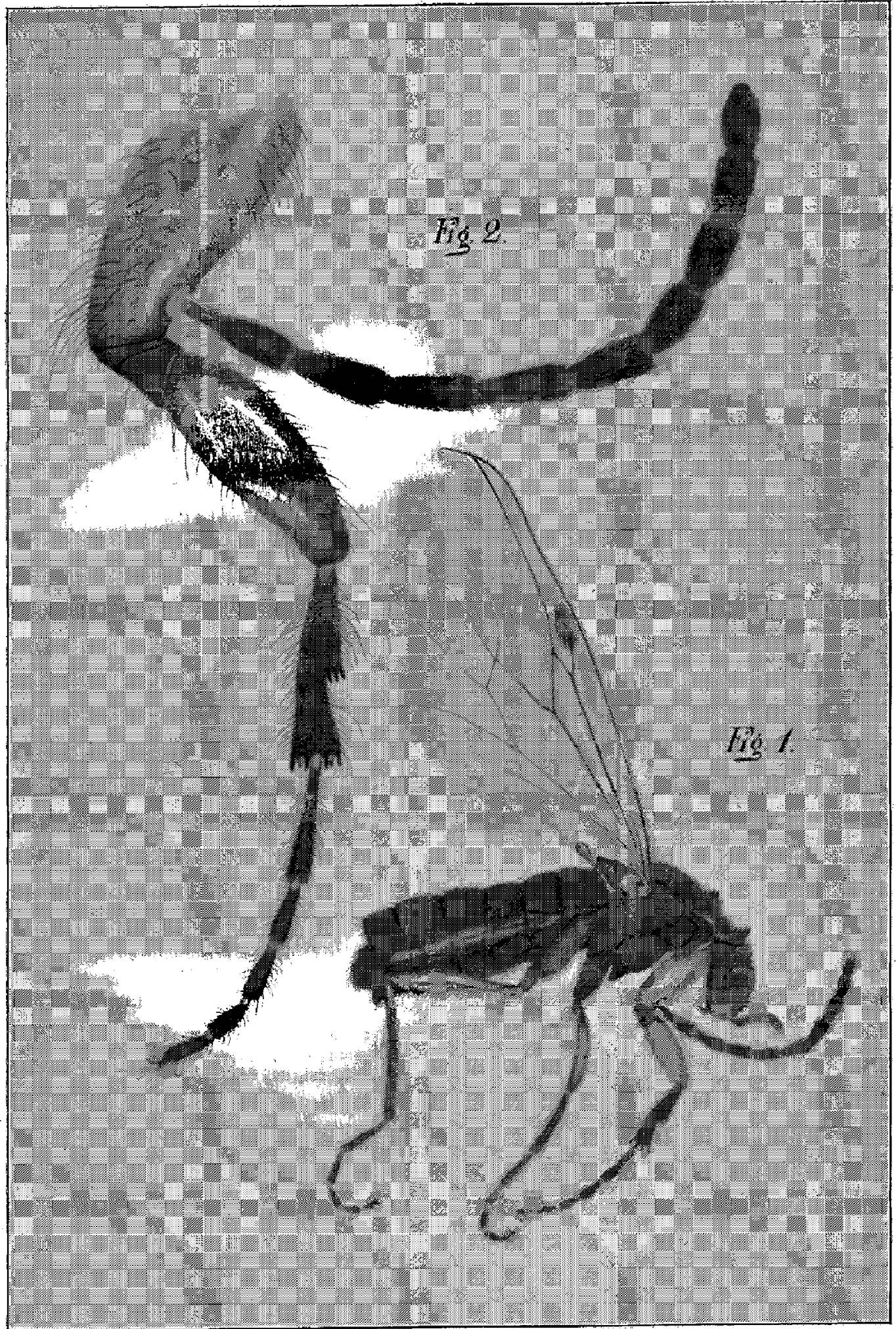

